\title{
Hepatoprotective Effect of Ganoderma applanatum Crude Polysaccharides on Carbon Tetrachloride-Induced Early Liver Fibrosis in Mice
}

\author{
Raden Joko Kuncoroningrat Susilo', , Dwi Winarni' ${ }^{1 *}$, Saikhu Akhmad Husen', Suhailah Hayaza', Sri Puji Astuti \\ Wahyuningsih', Ruey-An Doong ${ }^{1,2}$, Win Darmanto ${ }^{1, *}$
}

Raden Joko Kuncoroningrat

Susilo1, Dwi Winarni ${ }^{1, *}$, Saikhu

Akhmad Husen', Suhailah

Hayaza', Sri Puji Astuti

Wahyuningsih', Ruey-An

Doong $^{1,2}$, Win Darmanto ${ }^{1, *}$

'Department of Biology, Faculty of Science and Technology, Universitas Airlangga,

Surabaya 60115, INDONESIA

${ }^{2}$ Institute of Analytical and Environmental

Sciences, National Tsing Hua University, Sec.

2 Kuang Fu Road, Hsinchu 30013, TAIWAN.

\section{Correspondence}

\section{Win Darmanto}

Department of Biology, Faculty of Science and Technology, Universitas Airlangga,

Surabaya 60115, INDONESIA.

Phone no: +6285648283644

E-mail: windarmanto@fst.unair.ac.id

\section{Dwi Winarni}

Department of Biology, Faculty of Science and Technology, Universitas Airlangga,

Surabaya 60115, INDONESIA.

Phone no: +628175093047

E-mail: dwi-w@fst.unair.ac.id

History

- Submission Date: 30-06-2021;

- Review completed: 16-07-2021;

- Accepted Date: 09-08-2021.

DOI : 10.5530/pj.2021.13.181

Article Available online

http://www.phcogj.com/v13/i6

Copyright

(C) 2021 Phcogj.Com. This is an openaccess article distributed under the terms of the Creative Commons Attribution 4.0 International license.

\begin{abstract}
Introduction: Liver fibrosis is a treatable disease when still at early stages. Ganoderma applanatum plays role as alternative medicine. The fungi have antioxidant, anti-inflammatory, and anticancer bioactivities. This study aimed to evaluate the hepatoprotective effects of $G$. applanatum crude polysaccharides (GACP) on liver fibrosis due to $\mathrm{CCl}_{4}$ induction. Methods: This study was divided into six groups. BALB/c mice were given $\mathrm{CCl}_{4}$ dissolved in olive oil $(2 \mathrm{~mL} / \mathrm{kg} ; 1: 3)$ intraperitoneally (i.p) twice a week for four weeks to produce a liver fibrosis model. Distilled water (control group), silymarin $100 \mathrm{mg} / \mathrm{kg}$ and GACP 25, 50, $100 \mathrm{mg} / \mathrm{kg}$ were given once daily for four weeks. Alanine aminotransferase (ALT), aspartate aminotransferase (AST), tumor necrosis- $\alpha$ (TNF- $\alpha$ ) and interleukin-6 (IL-6) were determined by enzyme-linked immunosorbent assay (ELISA) kit. Histopathology was stained by hematoxylin \& eosin (H\&E) and Masson's trichome. Results: The administration of GACP effectively prevented ALT, AST, TNF- $\alpha$, and IL-6 levels from high elevation. Additionally, the GACP had protective effect after liver histological analysis exhibited less injury in the liver tissue. Conclusion: The hepatoprotective effect of GACP on liver fibrosis is mainly due to avoid high elevation of pro-inflammatory cytokine. This result revealed that GACP could be a potential hepatoprotective agent for later clinical therapy.
\end{abstract}

Key words: Anti-inflammatory, Carbon tetrachloride, Crude polysaccharides, Fibrosis, Ganoderma applanatum.

\section{INTRODUCTION}

The liver is known as central metabolism and detoxification for all type of hepatotoxic agents. ${ }^{1,2}$ Many factors can cause liver damage, such as viral infections, autoimmune diseases, and xenobiotic hepatotoxicity. Liver fibrosis is a wound healing process to reverse the liver injury chronic stage which is characterized by excess extracellular matrix due to liver inflammation. ${ }^{3,4}$ Fibrosis is generally associated with an unhealthy life such as alcohol consumption, obesity, genetic, hepatotoxicant, and hepatitis infections. Finally, liver fibrosis leads to more severe stages such as cirrhosis and hepatocellular carcinoma..$^{5-7}$ Carbon tetrachloride $\left(\mathrm{CCl}_{4}\right)$ is an environmental toxicant which potential to induce liver damage by increasing reactive free radicals. $\mathrm{CCl}_{4}$ metabolism by cytochrome $\mathrm{P} 450$ in endoplasmic reticulum affect an increase in trichloromethyl radicals $\left(\mathrm{CCl}_{3}^{*}\right)$ which play role in liver toxicity. ${ }^{8,9}$ Various types of P450 are present in the liver endoplasmic reticulum, one of them is cytochrome $\mathrm{P} 450$ 2E1 (CYP2E1) which is involved in metabolic processes and metabolic enzymes activation when liver injury by $\mathrm{CCl}_{4}$ induction. ${ }^{10,11}$ The pathogenicity of $\mathrm{CCl}_{4}$ in inducing liver damage includes many factors such as inflammation, oxidative stress, and apoptotic reactions. ${ }^{12,13}$ These $\mathrm{CCl}_{3}{ }^{*}$ bind nucleic acids, proteins, and lipids whereas these actions impair liver tissue via mutation, decreasing protein synthesis, and lipid peroxidation. All of injury pathways are end in hepatotoxic damage. ${ }^{14}$ Subsequently, this phase leads to inflammation pathway which increase several pro-inflammatory cytokines such IL-6 and TNF- $\alpha{ }^{15,16}$ Furthermore, hepatic stellate cells (HSCs) are quiescent cells that can be activated into myofibroblasts when they receive a stimulation from pro-inflammatory cytokines and growth factors. Thus, it plays an important role in chronic liver injury progress. Moreover, this process leads to produce additional extracellular matrix (ECM) components and into fibrosis stage. HSC activation is directly involved with increased collagen density. ${ }^{17,18}$ In particular, TNF- $\alpha$ and IL- 6 stimulate HSCs into myofibroblast stage. This transdifferentiation stage plays major role in producing ECM in wound healing process. Hence, the myofibroblast is key factor of fibrosis. ${ }^{19}$ Although, there have been significant advances in information regarding the molecular pathology of liver injury, there is still no alternative treatment that effectively prevents or treats liver fibrosis.

Silybum marianum (silymarin) has long been known as a liver therapy natural drug with high antioxidant and anti-inflammatory activities. ${ }^{20}$ Recently, extracts of natural ingredients are often used widely for the prevention of diseases in animals. Many studies have reported on natural antioxidants from polysaccharides, ketones, alkalis or glycosides in inhibiting reactive oxygen species (ROS) that induce liver damage. ${ }^{21,22}$ Polysaccharides are often a positive effect when used as herbal therapy against liver injury. Furthermore, they are also easily found in animals, plants and microbes. ${ }^{23}$ Ganoderma is one of the medicinal mushroom groups and being hepatoprotector agent with no side effects. The effectiveness of fungi absorption in the body through

Cite this article: Susilo RJK, Winarni D, Husen SA, Hayaza S, Wahyuningsih SPA, Doong RA, et al. Hepatoprotective Effect of Ganoderma applanatum Crude Polysaccharides on Carbon Tetrachloride-Induced Early Liver Fibrosis in Mice. Pharmacogn J. 2021;13(6): 1428-1436. 
clathrin and caveola mediated endocytosis route by micropinocytosis which is then absorbed by epithelial cells and circulated into the blood. ${ }^{24,25}$ Ganoderma polysaccharides have been proposed as bioactive components to prevent liver injury due to toxic substances. Previous studies have shown that polysaccharides have immunomodulatory, anticancer, anti-aging, antidiabetic, and liver protection activities. ${ }^{26}$ However, there is still missing information regarding possible mechanisms of liver protection. This study was designed to evaluate the hepatoprotective effects of GACP against $\mathrm{CCl}_{4}$ inducing liver fibrosis in mice.

\section{MATERIALS AND METHODS}

\section{Extract preparation}

G. applanatum was obtained from Tulungagung, East Java, Indonesia. Crude polysaccharides were generated from G. applanatum basidiocarp. The $400 \mathrm{~g}$ of $\mathrm{G}$. applanatum dry powder dissolved in $4 \mathrm{~L}$ water to a boil at $75^{\circ} \mathrm{C}$ for two times (three hours each). The insoluble portion was removed during filtration, and the supernatant was centrifuged $(2000 \times \mathrm{g} ; 10$ minutes $)$ and filtered again. The supernatant was collected and precipitated with absolute ethanol (1:4) three times. The precipitate was then dissolved into water and lyophilized. ${ }^{27}$

\section{Acute toxicity test}

The results of acute toxicity test were used to determine GACP extracts toxicities whether showed adverse effects or not. This test based on Organization for Economic Cooperation and Development (OECD) guidelines, 2002. Mice were divided into several groups with six mice of each group and administered with distilled water; and increasing dose start from $25 \mathrm{mg} / \mathrm{kg}, 50 \mathrm{mg} / \mathrm{kg}, 100 \mathrm{mg} / \mathrm{kg}, 200 \mathrm{mg} / \mathrm{kg}, 400 \mathrm{mg} /$ $\mathrm{kg}, 800 \mathrm{mg} / \mathrm{kg}$, and $1600 \mathrm{mg} / \mathrm{kg}$ body weight. The mice were kept in fast overnight but was still got free access water before treatment. The mice were also fed on 4 hours after dosing and were evaluated for $30 \mathrm{~min}$ and $2,3,4,24$ hours after dosing to progress information about any sign toxicity and clinical or toxicological symptoms.

\section{Experimental animal preparation and drug administration}

A total of 24 mice (4 weeks old, weighing 30-35 g) were used. Room temperature was kept at $25 \pm 1^{\circ} \mathrm{C}$, and relative humidity at $60 \pm 5 \%$. Mice were subjected to a 12 hours day/night cycle (lights turn on at $7 \mathrm{am}$ and turn off at $8 \mathrm{pm}$ ). All mice were acclimatized to laboratory conditions for one week prior to testing. During the test, the mice were given water and ad libitum feed and weighed every week to monitored their health condition. The mice were divided into six groups: normal control group: Oral distilled water (DW) and olive oil; model control group: $\mathrm{CCl}_{4}$ (Merck, Germany) and DW oral administration; silymarin group: Oral administration with silymarin $100 \mathrm{mg} / \mathrm{kg}$ and $\mathrm{CCl}_{4}$; low GACP: Oral administration $25 \mathrm{mg} / \mathrm{kg}$ and $\mathrm{CCl}_{4}$; medium GACP: Oral administration $50 \mathrm{mg} / \mathrm{kg}$ and $\mathrm{CCl}_{4}$; high GACP: Oral administration $100 \mathrm{mg} / \mathrm{kg}$ and $\mathrm{CCl}_{4}$. Inducing hepatic fibrosis, a dose of $2 \mathrm{~mL} / \mathrm{kg}$ bodyweight $\mathrm{CCl}_{4}$ was injected intraperitoneally (i.p) twice a week for four weeks (dissolved in olive oil; 1:3). Furthermore, DW, silymarin, and GACP were given per-oral once daily every day for four weeks. On the fifth week, the animals were sacrificed and the liver was taken for weighed, histological and biochemical evaluation, such as levels of inflammatory indicators. Liver weight index were measured with divided liver weight to body weight and the calculation results were multiplied with $100 \%$. All procedural animals were in accordance with the Ethics Commission of the Faculty of Veterinary Medicine, Universitas Airlangga (approval no. 2.KE.168.10.2018).

Liver physiological markers and pro-inflammatory cytokines analysis

The liver tissue was cut into ice-cold physiological saline with a homogenizer glass, and centrifuged at $3000 \times \mathrm{g}$ for 20 minutes at $4^{\circ} \mathrm{C}$ to produce $10 \%(\mathrm{w} / \mathrm{v})$ liver homogenate for laminin and $\mathrm{HA}$ test. Meanwhile, serum was obtained by centrifugation at the same instruction for alanine transaminase (ALT), aspartate transaminase (AST), TNF- $\alpha$ and IL-6. All of parameters were tested using an ELISA kit according to the instruction by manufacture (Bioassay Technology Laboratory, Shanghai, China).

\section{Histopathological examination}

The liver samples were prepared in $10 \%$ formalin and exposed to alcohol gradation, then immersed in paraffin. Liver sections were stained with (H\&E) and Masson's trichome for collagen staining based on standard procedures and observed under a light microscope. (CX51, Olympus, Tokyo, Japan) for histopathological examination. We used ImageJ software to analyze collagen density area.

\section{Data analysis}

Existing data were analyzed by one-way ANOVA test and Tukey post hoc test to intergroup significance, using SPSS 22.0 software (SPSS Inc, Chicago, IL, USA). Significant differences occurred when $\mathrm{p}<0.05$.

\section{RESULTS}

\section{Acute toxicity test}

Experimental toxicity test showed that no mortality and no side effects in mice which were administered with dose up to $1600 \mathrm{mg} / \mathrm{kg}$. The mice were still had normal and no sign of toxicity symptoms either on skin, furs, eyes and no behavioral changes, no massive body weight aberration, no digestion problem, no sleep disturbance. All of aspect were still normal as same as vehicle group. These findings gave evidence that GACP was safe and no toxic even in high doses.

\section{Effect of GACP on body weight and liver index in early liver fibrosis}

To determine hepatoprotective of GACP, the body weight and liver index were calculated. Data in Table 1 showed no significance $(\mathrm{p}>0.05)$ on week 1, week 2 and week 3 between treatment groups. However, measurement carried out during the study showed that administering $\mathrm{CCl}_{4}$ on week 4 significantly lowering body weight $(\mathrm{p}<0.05)$ in comparison with normal control group and also displayed the lowest weight value $(21.01 \pm 3.07 \mathrm{~g})$. On week 4 , All of GACP groups and silymarin exhibited significantly increased $(\mathrm{p}<0.05)$ compare than model control group and silymarin group showed a highest value $(36.07 \pm 4.16 \mathrm{~g})$. Furthermore, in Figure $1 \mathrm{~A}, \mathrm{CCl}_{4}$ was also significantly increased liver weight $(\mathrm{p}<0.05)$ in comparison with normal control group $(4.3 \pm 0.32 \mathrm{~g})$. Otherwise, GACP and silymarin were effectively prevented elevation of liver weight $(\mathrm{p}<0.05)$ after being comparison with model control group and silymarin group revealed the lowest $(1.3 \pm 0.08 \mathrm{~g})$. Hepatic index in Figure $1 \mathrm{~B}$ was significantly increased $(\mathrm{p}<0.05)$ after $\mathrm{CCl}_{4}$ induction compare with normal control group $(16.81 \pm 3.12 \%)$. However, giving GACP and silymarin were proven significantly warded off the increase in liver index $(\mathrm{p}<0.05)$ compared to the model control group and silymarin group exhibited the best value $(3.65 \pm 0.56 \%)$.

\section{Effect of GACP on ALT and AST levels in early liver fibrosis}

This study examined the serum levels of ALT and AST which were known as standard indicators of liver functionality. As shown in Figure 2A and Figure 2B, ALT and AST levels in model control group were significantly increased $(\mathrm{p}<0.05)$ in comparison with normal control group and displayed the highest biomarker levels (173.5 \pm 70 $\mathrm{U} / \mathrm{L} ; 484.25 \pm 174.64 \mathrm{U} / \mathrm{L}$, respectively), which indicated liver injury severity. The GACP treatment and silymarin showed significantly lower $(\mathrm{p}<0.05)$ ALT and AST levels compared to model control group 
Table 1: Effect of GACP on body weight in mice induced by $\mathrm{CCl}_{4}$.

\begin{tabular}{|c|c|c|c|c|c|}
\hline \multirow{2}{*}{ Drugs } & \multicolumn{5}{|c|}{ Body weight (g) } \\
\hline & Before $\mathrm{CCl}_{4}$ & Week 1 & Week 2 & Week 3 & Week 4 \\
\hline Control & $24.98 \pm 7.1$ & $32.6 \pm 6.69$ & $34.52 \pm 5.7$ & $34.51 \pm 5.48$ & $34.85 \pm 4.75$ \\
\hline Model & $24.76 \pm 3.25$ & $23.96 \pm 2.4$ & $23.11 \pm 3.05$ & $23.01 \pm 2.78$ & $21.01 \pm 3.07^{*}$ \\
\hline $\mathrm{GACP} 25+\mathrm{CCl}_{4}$ & $24.53 \pm 5.44$ & $24.15 \pm 1.12$ & $27.01 \pm 1.54$ & $28.54 \pm 1.52$ & $29.79 \pm 3.61^{\#}$ \\
\hline $\mathrm{GACP} 50+\mathrm{CCl}_{4}$ & $25.77 \pm 6.31$ & $28.45 \pm 6.28$ & $28.38 \pm 6.02$ & $28.79 \pm 6.08$ & $28.92 \pm 7.15^{\#}$ \\
\hline $\mathrm{GACP} 100+\mathrm{CCl}_{4}$ & $24.65 \pm 6.8$ & $29.71 \pm 3.57$ & $31.92 \pm 2.87$ & $31.83 \pm 2.01$ & $32.2 \pm 2.4^{\#}$ \\
\hline Silymarin $+\mathrm{CCl}_{4}$ & $24.5 \pm 4.93$ & $31.47 \pm 3.29$ & $33.92 \pm 3.21$ & $34.55 \pm 3.38$ & $36.07 \pm 4.16^{\#}$ \\
\hline
\end{tabular}

Note: GACP: Ganoderma applanatum crude polysaccharides. All values are the means $\pm S D(n=6)$. ${ }^{*}<<0.05$ vs control group; ${ }^{*} p<0.05$ vs model group.

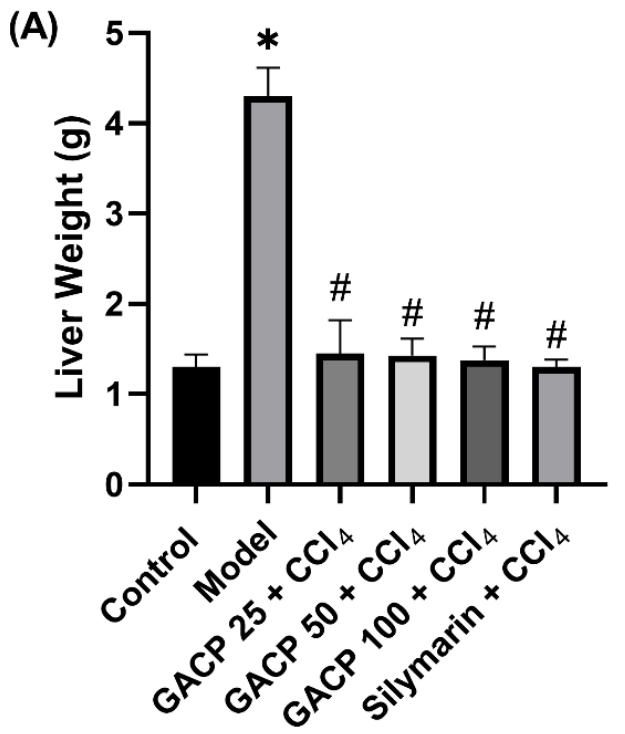

(B)

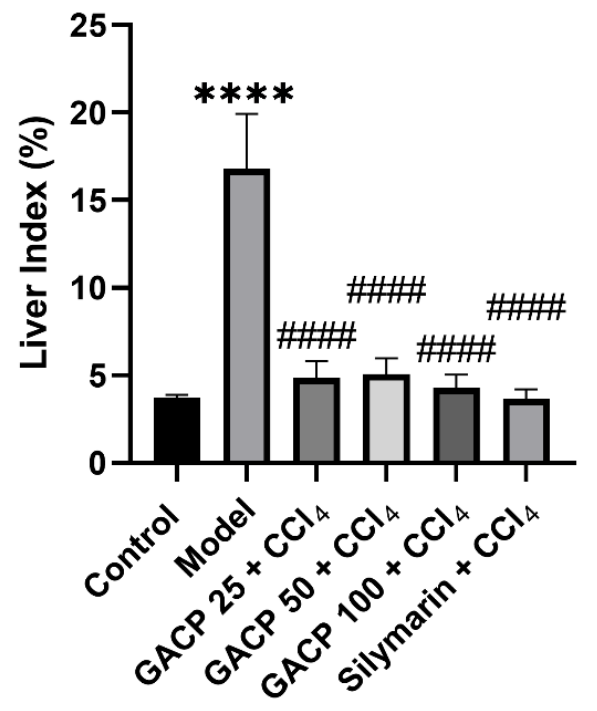

Figure 1: Effect of GACP on liver weight (A) and liver index (B) in mice induced by CCI4. Data express the mean \pm SD $(n=$ $6)$. ${ }^{*}<<0.05$ vs control group; ${ }^{* * * *} p<0.0001$ vs control group; \#p<0.05 vs model group; \#\#\#\#<0.0001 vs model group.

(A)

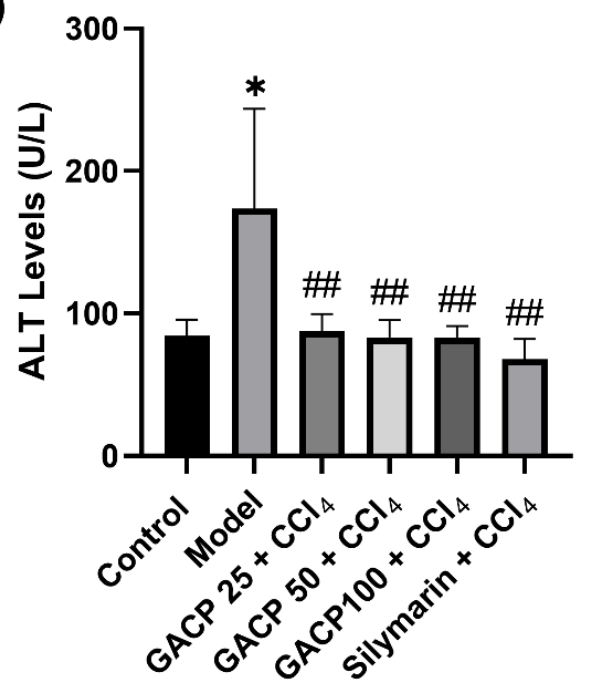

(B)

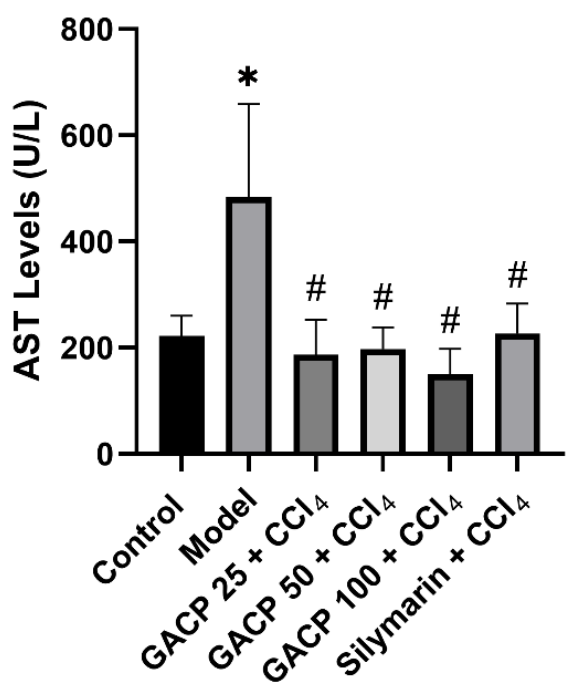

Figure 2: Effect of GACP on ALT (A) and AST (B) levels in mice induced by CCI4. Data express the mean \pm SD $(n=6)$. ${ }^{*} p<0.05$ vs control group; $\# p<0.05$ vs model group; \#\#p<0.01 vs model group. ALT: Alanine transaminase; AST: Aspartate transaminase. 
and GACP $100 \mathrm{mg} / \mathrm{kg}$ dose group exhibited the lowest levels value (83 $\pm 8.12 \mathrm{U} / \mathrm{L} ; 150.25 \pm 47.09 \mathrm{U} / \mathrm{L}$, respectively). These things described about potential protection of GACP extracts against liver injury.

Effect of GACP on TNF-a and IL-6 levels in early liver fibrosis

The serum levels of pro-inflammatory cytokines such as TNF- $\alpha$ and IL-6 are closely related to the initiation of inflammation as a fibrosis stimulator via inflammation pathway. On Figure 3A and Figure 3B showed that model control group significantly increased $(\mathrm{p}<0.05)$ TNF- $\alpha$ and IL- 6 levels compared to the normal control group and give the highest value $(26.93 \pm 12.28 \mathrm{ng} / \mathrm{L} ; 4 \pm 0.99 \mathrm{pg} / \mathrm{mL}$, respectively). Meanwhile, GACP and silymarin inductions to the treatment groups effectively prevented escalation $(\mathrm{p}<0.05)$ of TNF- $\alpha$ and IL-6 levels. Furthermore, GACP $100 \mathrm{mg} / \mathrm{kg}$ dose group was the most effective dose in avoid elevation of TNF- $\alpha$ and IL-6 levels $(5.78 \pm 0.7 \mathrm{ng} / \mathrm{L} ; 1.01 \pm 0.04$ $\mathrm{pg} / \mathrm{mL}$, respectively). The results displayed that GACP inhibited proinflammatory cytokines elevation too.

\section{Effect of GACP on liver histopathological in early liver fibrosis}

Histological evaluation is important to determine the degree of liver injury due to $\mathrm{CCl}_{4}$ and effect of GACP in defending the liver tissue from that liver injury. This histological study using HE staining for identification of damage form and Masson's trichome staining to evaluated collagen density in liver tissue. As shown in Figure 4, the normal control group showed normal structures in the liver tissue, and sinusoid and central veins were still formed normally too. In contrary, $\mathrm{CCl}_{4}$ injection in model control group revealed necrosis, ballooning hepatocytes, inflammatory infiltration vastly in surrounding central vein. Meanwhile, the silymarin group showed prevented this injury with less inflammatory infiltration and necrosis. Moreover, there was no ballooning in silymarin group. Giving GACP at dose $25 \mathrm{mg} / \mathrm{kg}$ was still found fairly high necrosis and inflammatory infiltration, but ballooning cells were gone. In dose $50 \mathrm{mg} / \mathrm{kg}$ of GACP, necrosis cells remain as well as inflammatory infiltration. Furthermore, the GACP dose $100 \mathrm{mg} / \mathrm{kg}$ displayed less necrosis and inflammatory infiltration but no ballooning cells were observed. Masson Trichome's staining as in Figure 5A, showed about the normal control group with a clear hepatic structure and no collagen formation in liver tissue. Induction of $\mathrm{CCl}_{4}$ in model control group showed little collagen fiber formation, especially in central vein area.

This formation was still not produced septa yet, but Masson's trichome staining had already exhibited that for 4 weeks, $\mathrm{CCl}_{4}$ injection caused this little fibrotic formation. Meanwhile, giving silymarin displayed liver amelioration with less collagen fiber which was indicated by yellow arrow. The dose $25 \mathrm{mg} / \mathrm{kg}$ of GACP revealed mild collagen fiber in central vein area compared with model control group. Moreover, GACP dose $50 \mathrm{mg} / \mathrm{kg}$ group exhibited mild collagen fiber too in central vein area. Hereafter, dose $100 \mathrm{mg} / \mathrm{kg}$ of GACP showed very delicate collagen fiber deposit in surrounding central vein area. Producing the least compared to other GACP groups and barely visible formation. Meanwhile, statistical analyzed for collagen density in Figure $5 B$, $\mathrm{CCl}_{4}$ was also significantly increased collagen density $(\mathrm{p}<0.05)$ in comparison with normal control group and displayed highest value than other groups $(21.7 \pm 5.66 \%)$. Silymarin and all of GACP groups exhibited significantly different which still remain low compared than model control groups $(\mathrm{p}<0.05)$. In addition, silymarin produced the best result in prevented elevation of collagen density between other groups $(4.73 \pm 0.98 \%)$. This histopathological and statistic results ensured that GACP plays role in protective effects against liver fibrosis.

\section{DISCUSSION}

As primary source of ECM in liver fibrosis, quiescent HSCs are transdifferentiated into myofibroblast-cell like caused by inflammation factors such as TNF- $\alpha$ and IL- $6 .{ }^{17,28}$ Carbon tetrachloride induction which gave in this study was proven to impair liver tissue with continuous injury response become irreversible injury later., ${ }^{6,29}$ The development of effective treatment pathways and methods is desperately need now. Further research in either advance or traditional medicine is still carried out to solve the problem about how to treat fibrosis effectively with less side effects. In the present study, GACP was chosen as alternative medicine showed the significant effects to attenuate fibrosis factors. Firstly, after $\mathrm{CCl}_{4}$ induction, the weighing
(A)

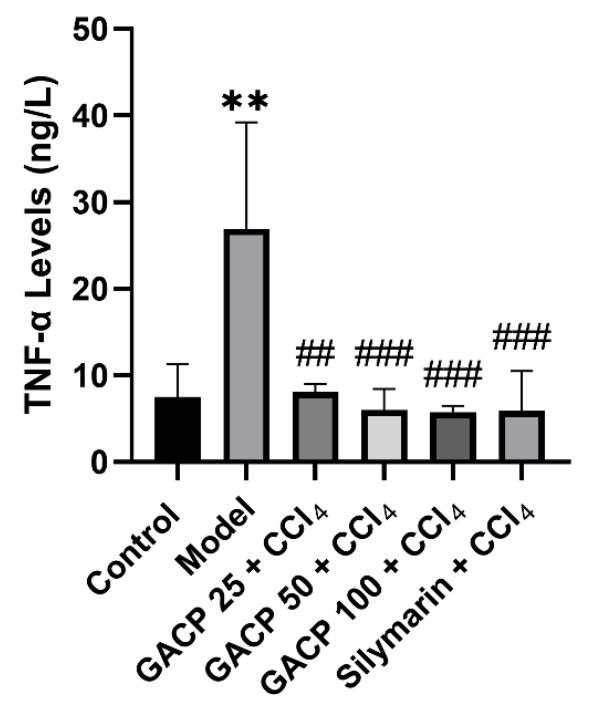

(B)

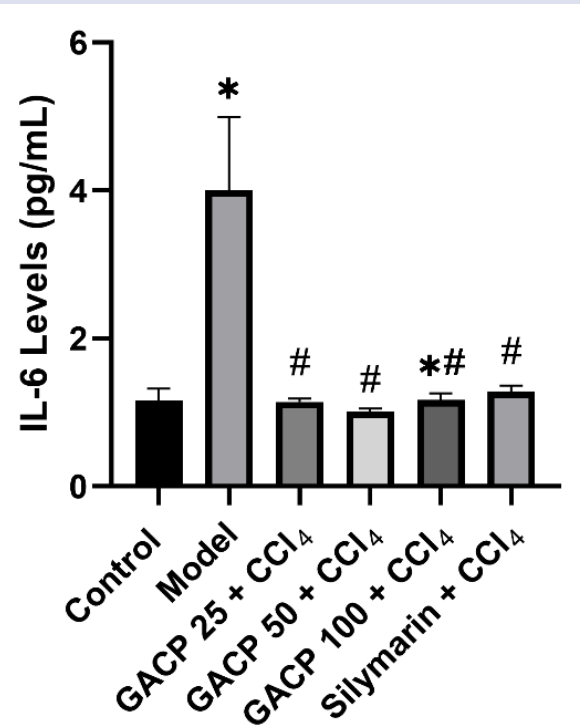

Figure 3: Effect of GACP on TNF- $\alpha(A)$ and IL- 6 (B) levels in mice induced by CCl4. Data express the mean \pm SD $(n=6)$. ${ }^{*} p<0.05$ vs control group; ${ }^{* *} p<0.01$ vs control group; $\# p<0.05$ vs model group; \#\#p<0.01 vs model group; \#\#\#<0.001 vs model group. TNF- $\alpha$ : Tumor necrosis factor- $\alpha$; IL-6: Interleukin- 6 . 


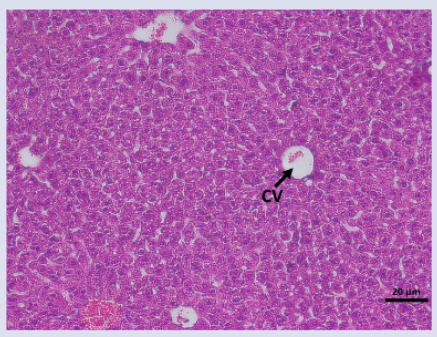

Control

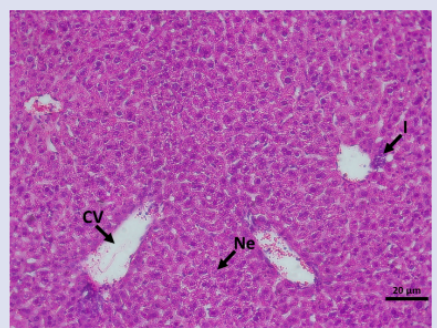

GACP $50+\mathrm{CCl}_{4}$

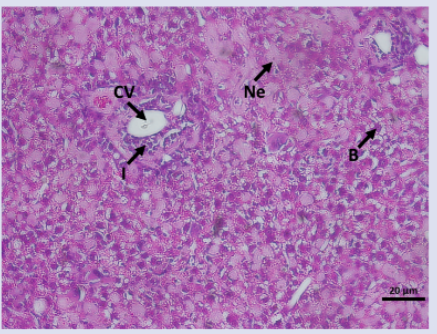

Model

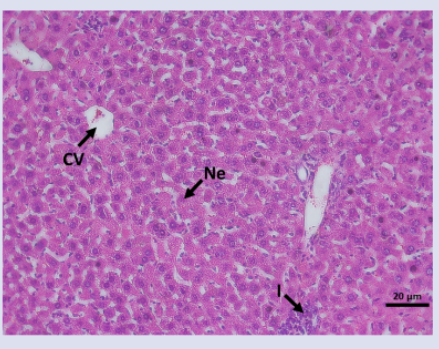

GACP $100+\mathrm{CCl}_{4}$

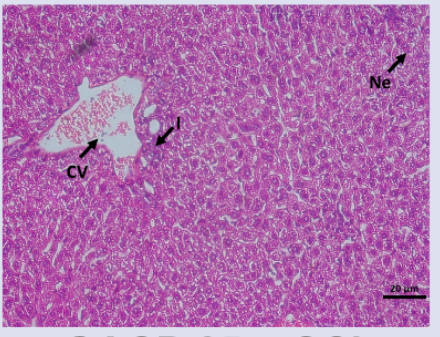

$\mathrm{GACP} 25+\mathrm{CCl}_{4}$

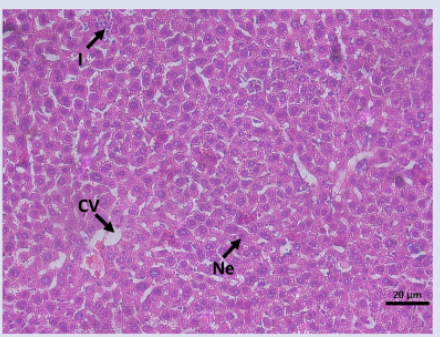

Silymarin $+\mathrm{CCl}_{4}$

Figure 4: Effect of GACP on liver histology in mice with H\&E staining (magnification, $\times 200$ ). B: Ballooning hepatocyte; CV: Central vein; I: Inflammatory infiltration; Ne: Necrosis.

(A)

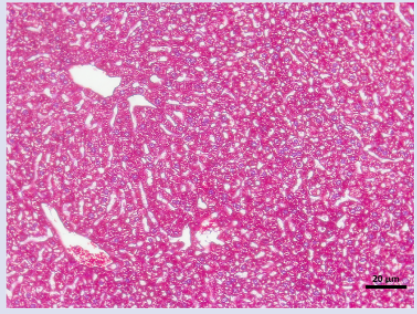

Control

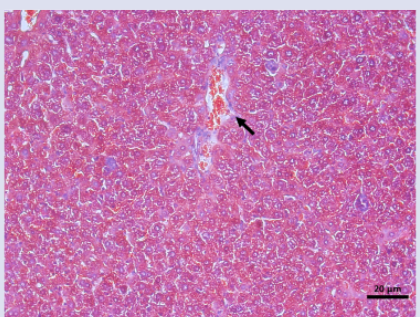

GACP $50+\mathrm{CCl}_{4}$

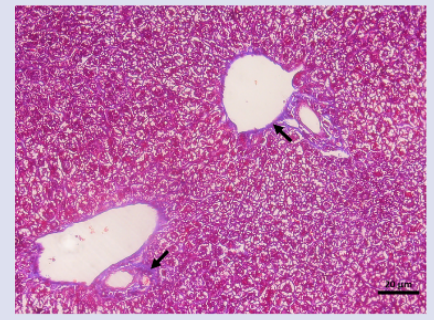

Model

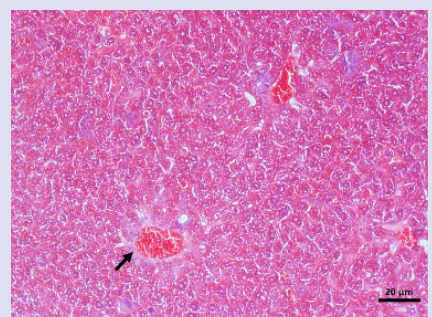

GACP $100+\mathrm{CCl}_{4}$

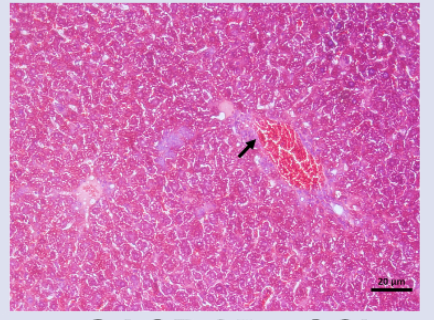

GACP $25+\mathrm{CCl}_{4}$

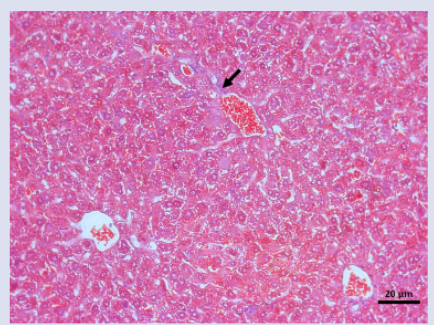

Silymarin $+\mathrm{CCl}_{4}$

(B)

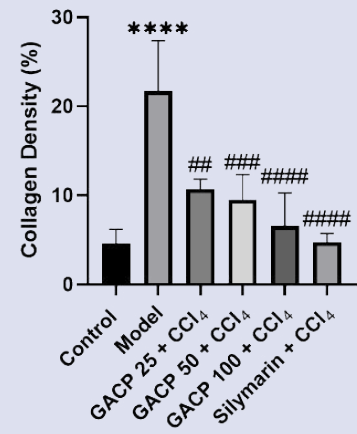

Figure 5: Effect of GACP on liver fibrosis in mice with Masson's trichome staining (magnification, $\times 200)(A)$. Black arrow showing the collagen area. Semi-quantitative analysis of collagen density $(B)$. Data express the mean $\pm S D(n=6)$.

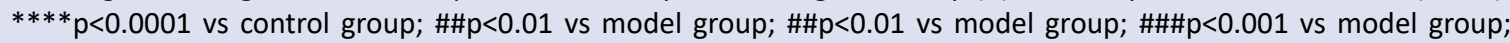
$\# \# \#$ $<0.0001$ vs model group. 
displayed reducing value on every week and reach significant on week 4. Administered of GACP could elevated the weighing which is related to the role of GACP as a supplement with giving so much nutrition such as arginine, glutamic acid, aspartic acid, tryptophan, and lysine. The nutrition works in accelerate body metabolism to dispose many toxins from the body. ${ }^{30}$

Decreasing in liver weight and liver index explained that GACP play role in liver mass via decreasing collagen component which increase the weight of liver. ${ }^{31}$ In this study, the degree of liver injury was indicated by measuring the levels of liver enzyme biomarkers. $\mathrm{CCl}_{4}$ induction could significantly increase ALT and AST levels compared to the normal control group. This event was occurred due to the release of these hepatic enzymes into the bloodstream after being necrosis in liver cell. ${ }^{32}$ Both of enzymes, especially, ALT is known as specific enzymes for liver injury due to their limited distribution in other organs as we know that the origin of enzyme is derived from liver cytoplasm. Meanwhile, AST is generally associated with liver and another organ injury such as the heart, muscles, kidneys, bones and brain. Increase in AST levels is indeed a benchmark of liver injury stage but no absolute due to the levels are quite a lot in other organs. ${ }^{33}$ However, AST can still be used as reference considering that its origin is fairly high in the mitochondria and cytoplasm of liver. Furthermore, treatment with GACP and silymarin showed protective activity which marked by decreasing hepatic enzymes. This indicates that GACP can trigger liver cell regeneration and reduce the leakage of hepatic enzymes in cells. In the chronic stage of damage, as injury's response, NF- $\kappa \mathrm{B}$ will activates and stimulates Kupffer cell (resident macrophage) to produce pro-inflammatory cytokines in HSCs activation. ${ }^{34-37}$

This activation aims to maintain homeostasis and also begin wound healing process whereas pro-inflammatory cytokine takes pivotal role accelerate myofibroblast-cell like transdifferentiation. TNF- $\alpha$ and IL-6 are pro-inflammatory cytokine that involved in fibrosis formation. Associated via inflammation pathways. ${ }^{34-37}$ TNF- $\alpha$ is one of the pro-inflammatory cytokines which mainly produced by macrophage. In fibrosis, this cytokine acts on myofibroblastcell like and apoptotic activator. Moreover, IL-6 was produced by macrophage and HSCs along with hepatomitogen and also plays in accelerating transdifferentiation. ${ }^{38-40}$ Hence, inhibition of the inflammatory factor impacts to attenuate liver fibrosis. ${ }^{41}$ This study showed that $\mathrm{CCl}_{4}$ administration significantly increased the recruitment of the inflammatory factor compared to the normal group. Furthermore, GACP extracts play as an antagonist against the attack of pro-inflammatory cytokines which significantly decreased fibrosis process. To determine GACP effects in liver tissue, we observed liver injury's parameters by histological evaluation. Inducing by $\mathrm{CCl}_{4}$ causes necrosis, hydropic, ballooning hepatocytes, and inflammatory infiltration. $\mathrm{CCl}_{4}$ toxicities impair cells by homeostasis failure whereas excessive water is stuck in the cell leading to ballooning stage and ends with necrosis. ${ }^{8}$ In contrast, distinct improvement was displayed by GACP administration when could ameliorate injury parameters. As we explain in discussion above, GACP could significantly decrease pro-inflammatory factor which reduced injury response trigger to proliferate cells that repairing liver tissue. ${ }^{41}$ HSCs activation was associated with an increase in collagen density. Hence, GACP as antiinflammatory create a sequencing mechanism whereas these natural compounds obstruct further chronic injury state and the fibrosis mechanism with no exception. ${ }^{42,43}$ Meanwhile, Masson's trichome staining both of histological and statistical exhibited improvement after administrate with GACP. Collagen area which stained blue area significantly alleviate in comparison with model control group, also in statistical being decreased too. These results indicate that GACP effectively against $\mathrm{CCl}_{4}$-induced hepatotoxicity in mice liver fibrosis, and its mechanism is related to improving metabolic function, inhibiting inflammatory reactions, and decreasing collagen density in hepatic tissue.

\section{CONCLUSION}

In summary, GACP showed hepatoprotective potential against early liver fibrosis through prevent pro-inflammatory cytokines elevation and collagen density. These results indicate that GACP effectively as a protector against liver fibrosis. Further clinical trial research should be conducted and fibrosis therapy in human should be with new alternative treatment methods.

\section{ACKNOWLEDGEMENTS}

This study was support by PMDSU research grant from Ministry of Research, Technology, and Higher Education in Indonesia (1520/ $\mathrm{UN} 3 / 2019)$.

\section{REFERENCES}

1. Pandit A, Sachdeva T, Bafna P. Drug-induced hepatoxicity: A review. J Appl Pharm Sci. 2012;02:233-243.

2. Singh D, Cho WC, Upadhyay, G. Drug-induced liver toxicity and prevention by herbal antioxidants: An overview. Front Physiol. 2016;6:363.

3. Arriazu E, Ruiz de Galarreta M, Cubero FJ, Varela-Rey M, Pérez de Obanos MP, Leung TM, Lopategi A, Benedicto A, AbrahamEnachescu I, Nieto N. Extracellular matrix and liver disease. Antioxid Redox Signal. 2014;21:1078-97.

4. Li J, Pan Y, Kan M, Xiao X, Wang Y, Guan F, Zhang X, Chen L. Hepatoprotective effects of berberine on liver fibrosis via activation of AMP-activated protein kinase. Life Sci. 2014;98:24-30.

5. Suk KT, Kim DJ. Staging of liver fibrosis or cirrhosis: The role of hepatic venous pressure gradient measurement. World J Hepatol. 2015;7:607-15

6. Zhang M, Wang Y, Zhu G, Sun C, Wang J. Hepatoprotective effect and possible mechanism of phytoestrogen calycosin on carbon tetrachloride-induced liver fibrosis in mice. Naunyn Schmiedebergs Arch Pharmacol. 2021;394:189-204

7. O'Rourke JM, Sagar VM, Shah T, Shetty S. Carcinogenesis on the background of liver fibrosis: Implications for the management of hepatocellular cancer. World J Gastroenterol. 2018;24:4436-4447.

8. Lee YS, Cho IJ, Kim KW, Lee MK, Ku SK, Choi JS, Lee HJ Hepatoprotective effects of blue honeysuckle on $\mathrm{CCl}_{4}$-induced acute liver damaged mice. Food Sci Nutr. 2018;7:322-338.

9. Weber LW, Boll M, Stampfl A. Hepatotoxicity and mechanism of action of haloalkanes: Carbon tetrachloride as a toxicological model. Crit Rev Toxicol. 2003;33:105-36.

10. Peter Guengerich F, Avadhani NG. Roles of cytochrome P450 in metabolism of ethanol and carcinogens. Adv Exp Med Biol. 2018;1032:15-35.

11. Lu Y, Cederbaum Al. CYP2E1 and oxidative liver injury by alcohol Free Radic Biol Med. 2008;44:723-38.

12. Li S, Hong M, Tan HY, Wang N, Feng $Y$. Insights into the role and interdependence of oxidative stress and inflammation in liver diseases. Oxid Med Cell Longev. 2016;2016:4234061.

13. Wang M, Niu J, Ou L, Deng B, Wang Y, Li S. Zerumbone protects against carbon tetrachloride $\left(\mathrm{CCl}_{4}\right)$-induced acute liver injury in mice via inhibiting oxidative stress and the inflammatory response: Involving the TLR4/NF-KB/COX-2 pathway. Molecules. 2019;24:1964.

14. Scholten D, Trebicka J, Liedtke C, Weiskirchen R. The carbon tetrachloride model in mice. Lab Anim. 2015;49:4-11.. 
15. Zhang JM, An J. Cytokines, inflammation, and pain. Int Anesthesiol Clin. 2007;45;27-37.

16. Bringardner $\mathrm{BD}$, Baran $\mathrm{CP}$, Eubank TD, Marsh $\mathrm{CB}$. The role of inflammation in the pathogenesis of idiopathic pulmonary fibrosis. Antioxid Redox Signal. 2008;10:287-301.

17. Higashi T, Friedman SL, Hoshida Y. Hepatic stellate cells as key target in liver fibrosis. Adv Drug Deliv Rev. 2017;121:27-42.

18. Duan X, Zhu H. Hepatoprotective effects of Dicliptera chinensis polysaccharides on dimethylnitrosamine-induced hepatic fibrosis rats and its underlying mechanism. J Ethnopharmacol. 2016;179:3844.

19. Bochaton-Piallat ML, Gabbiani G, Hinz B. The myofibroblast in wound healing and fibrosis: answered and unanswered questions. F1000Res. 2016;5:F1000 Faculty Rev-752.

20. Surai PF. Silymarin as a natural antioxidant: An overview of the current evidence and perspectives. Antioxidants (Basel). 2015;4:204-47.

21. Latief $U$, Ahmad R. Herbal remedies for liver fibrosis: A review on the mode of action of fifty herbs. J Tradit Complement Med. 2017;8:352-360.

22. Liu $\mathrm{Q}$, Zhu M, Geng X, Wang H, Ng TB. Characterization of polysaccharides with antioxidant and hepatoprotective activities from the edible mushroom Oudemansiella radicata. Molecules. 2017;22:234

23. Li Q, Niu Y, Xing P, Wang C. Bioactive polysaccharides from natural resources including Chinese medicinal herbs on tissue repair. Chin Med. 2018;13:7.

24. Behzadi S, Serpooshan V, Tao W, Hamaly MA, Alkawareek MY, Dreaden EC, Brown D, Alkilany AM, Farokhzad OC, Mahmoudi M. Cellular uptake of nanoparticles: Journey inside the cell. Chem Soc Rev. 2017;46:4218-4244.

25. Soares AA, de Sá-Nakanishi AB, Bracht A, da Costa SM, Koehnlein EA, de Souza CG, Peralta RM. Hepatoprotective effects of mushrooms. Molecules. 2013;18:7609-30.

26. Cör D, Knez Ž, Knez Hrnčič M. Antitumour, antimicrobial, antioxidant and antiacetylcholinesterase effect of Ganoderma lucidum terpenoids and polysaccharides: A review. Molecules;2018:23, 649.

27. Susilo RJK, Winarni $D$, Husen SA, Hayaza $S$, Punnapayak $H$, Wahyuningsih SPA, Sajidah ES, Darmanto W. Hepatoprotective effect of crude polysaccharides extracted from Ganoderma lucidum against carbon tetrachloride-induced liver injury in mice. Vet World. 2019;12:1987-1991.

28. Khomich O, Ivanov AV, Bartosch B. Metabolic hallmarks of hepatic stellate cells in liver fibrosis. Cells. 2019;9:24.
29. Xue $M$, Jackson CJ. Extracellular matrix reorganization during wound healing and its impact on abnormal scarring. Adv Wound Care (New Rochelle). 2015;4:119-136.

30. Sharifi-Rad J, Butnariu M, Ezzat SM, Adetunji CO, Imran M, Sobhani SR, Tufail T, Hosseinabadi T, Ramírez-Alarcón K, Martorell M, Maroyi A, Martins N. Mushrooms-rich preparations on wound healing: From nutritional to medicinal attributes. Front Pharmacol. 2020;11:567518

31. Vargas-Mendoza N, Madrigal-Santillán E, Morales-González A Esquivel-Soto J, Esquivel-Chirino C, García-Luna Y, González-Rubio M, Gayosso-de-Lucio JA, Morales-González JA. Hepatoprotective effect of silymarin. World J Hepatol. 2014;6:144-9.

32. Liu G, Liu X, Zhang Y, Zhang F, Wei T, Yang M, Wang K, Wang Y, Liu $\mathrm{N}$, Cheng $\mathrm{H}$, Zhao Z. Hepatoprotective effects of polysaccharides extracted from Zizyphus jujube cv. Huanghetanzao. Int J Biol Macromol. 2015;76:169-75.

33. McGill MR. The past and present of serum aminotransferases and the future of liver injury biomarkers. EXCLI J. 2016;15:817-828.

34. Fujita T, Narumiya S. Roles of hepatic stellate cells in liver inflammation: A new perspective. Inflamm Regen. 2016;36:1-6.

35. Gao G. Hepatoprotective and anti-inflammatory cytokines in alcoholic liver disease. J Gastroenterol Hepatol. 2012;27:89-93.

36. Woolbright $\mathrm{BI}$, Jaeschke $\mathrm{H}$. Mechanisms of inflammatory liver injury and drug-induced hepatotoxicity. Curr Pharmacol Rep. 2018;4:346357.

37. Elpek GÖ. Cellular and molecular mechanisms in the pathogenesis of liver fibrosis: An update. World J Gastroenterol. 2014;20:726076.

38. Czauderna C, Castven D, Mahn FL, Marquardt JU. Contextdependent role of NF-KB signaling in primary liver cancer-from tumor development to therapeutic implications. Cancers (Basel). 2019;11:1053.

39. Elsharkawy AM, Mann DA. Nuclear factor-kappaB and the hepatic inflammation-fibrosis-cancer axis. Hepatology. 2007;46:590-7.

40. Weiskirchen R. Hepatoprotective and anti-fibrotic agents: It's time to take the next step. Front Pharmacol. 2016;6:303.

41. Lam $P$, Cheung $F$, Tan HY, Wang N, Yuen MF, Feng $Y$. Hepatoprotective effects of Chinese medicinal herbs: A focus on anti-inflammatory and anti-oxidative activities. Int J Mol Sci. 2016;17:465

42. Khomich O, Ivanov AV, Bartosch B. Metabolic hallmarks of hepatic stellate cells in liver fibrosis. Cells. 2019;9:24.

43. Gao HY, Li GY, Lou MM, Li XY, Wei XY, Wang JH. Hepatoprotective effect of Matrine salvianolic acid $B$ salt on carbon tetrachlorideinduced hepatic fibrosis. J Inflamm (Lond). 2012;9:16. 


\section{GRAPHICAL ABSTRACT}

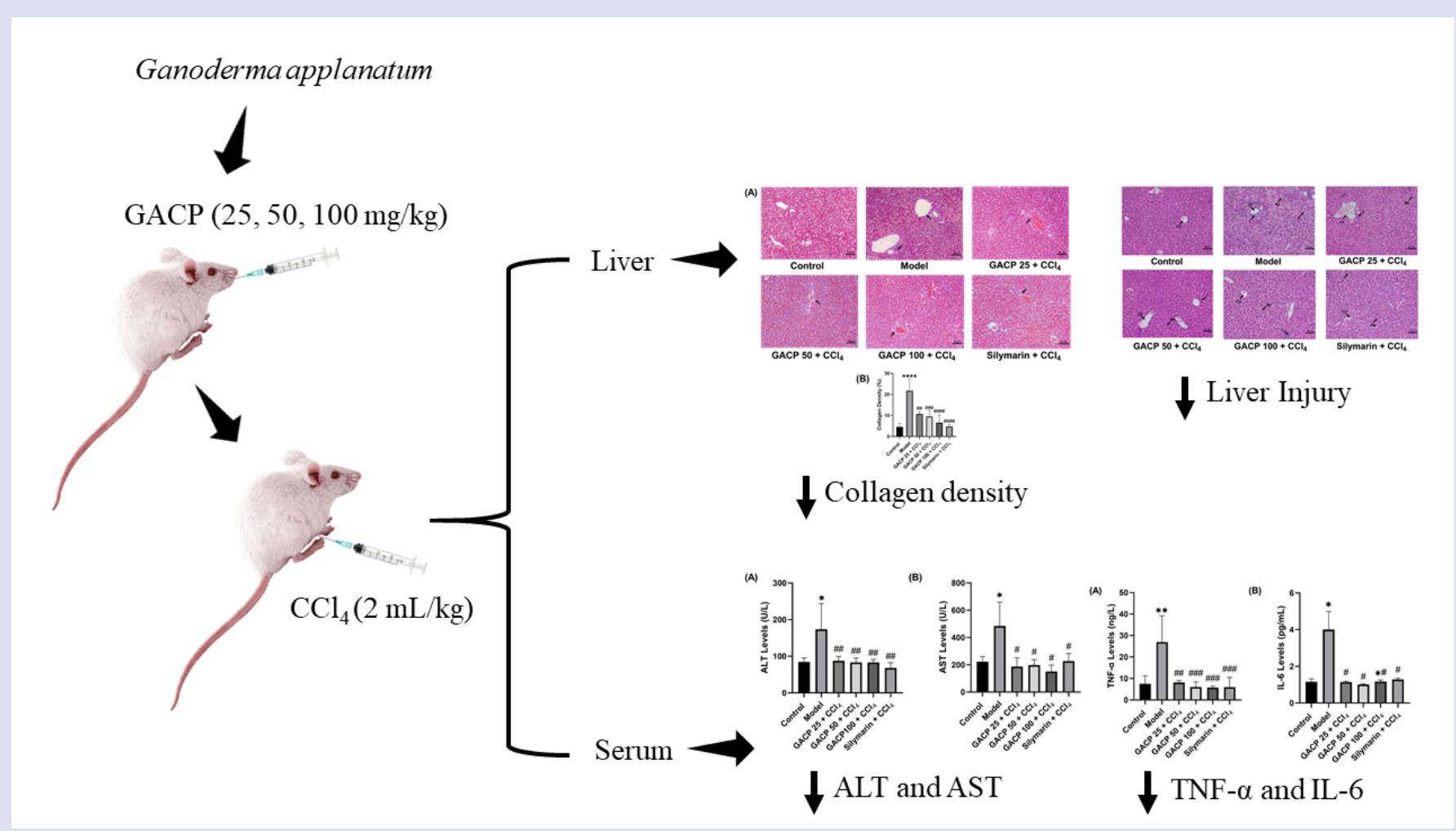

\section{ABOUT AUTHORS}

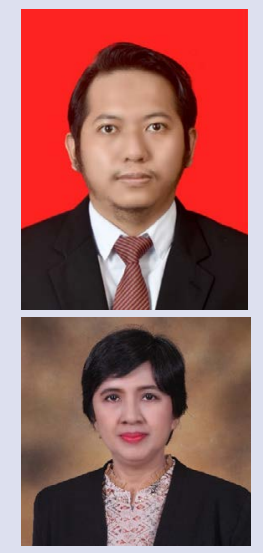

Raden Joko Kuncoroningrat Susilo: $\mathrm{He}$ is a doctoral student from Faculty of Science and Technology, Universitas Airlangga. He is also got his bachelor and master from Department Biology, Faculty of Science and Technology, Universitas Airlangga. Recently, he is work in alternative medicine of liver fibrosis and liver cancer.

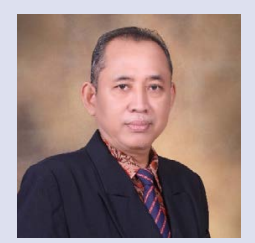

Dwi Winarni: She is a lecturer at Department of Biology, Faculty of Science and Technology, Universitas Airlangga. She is also Associate Professor in Animal Physiology. She got her doctoral from Universitas Airlangga. She mainly focused in liver fibrosis and sea cucumber research.

Saikhu Akhmad Husen: He is a lecturer at Department of Biology, Faculty of Science and Technology, Universitas Airlangga. He is also Associate Professor in Animal Physiology. He got his doctoral from Universitas Airlangga. He is interest in animal diabetes and liver injury research.

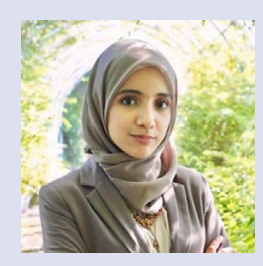

Suhailah Hayaza: He is a doctoral student from Faculty of Science and Technology, Universitas Airlangga. She is also got her bachelor and doctoral from Department Biology, Faculty of Science and Technology, Universitas Airlangga. She is work in alternative medicine of liver cancer and immunosurveillance. 


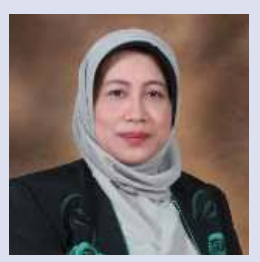

Sri Puji Astuti Wahyuningsih: She is a lecturer at Department of Biology, Faculty of Science and Technology, Universitas Airlangga. She is also Professor in Animal Physiology. She got her doctoral from Universitas Airlangga. Currently, she focused on alternative medicine of liver cancer research.

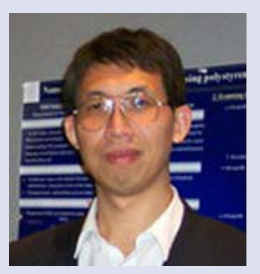

Ruey-an Doong: $\mathrm{He}$ is a lecturer at Institute of Analytical and Environmental Sciences, National Tsing Hua University. He is also Professor at National Tsing Hua University. He got his Ph.D from Environmental Engineering, National Taiwan University. Currently, he works in Environmental Chemistry, Nanosensing Technology, Materials Chemistry, and Nanotechnology research.

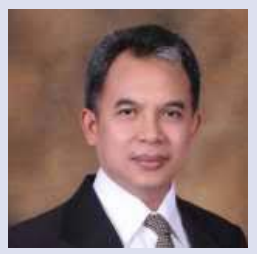

Win Darmanto: He is a lecturer at Department of Biology, Faculty of Science and Technology, Universitas Airlangga. He is also Professor in Teratology and Molecular Biology. He got his Ph.D from Nagoya University. He is interest in liver injury and cancer research.

Cite this article: Susilo RJK, Winarni D, Husen SA, Hayaza S, Wahyuningsih SPA, Doong RA, et al. Hepatoprotective Effect of Ganoderma applanatum Crude Polysaccharides on Carbon Tetrachloride-Induced Early Liver Fibrosis in Mice. Pharmacogn J. 2021;13(6): 1428-1436. 